\title{
The chemotactic swimming behavior of bird schistosome miracidia in the presence of compatible and incompatible snail hosts
}

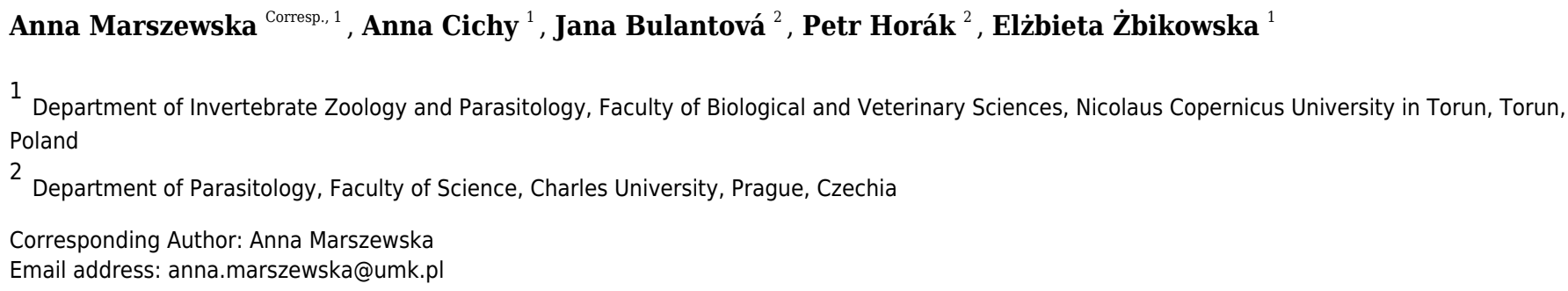

No effective method has yet been developed to prevent the threat posed by the emerging disease - cercarial dermatitis (swimmer's itch), caused by infective cercariae of bird schistosomes (Digenea: Schistosomatidae). In our previous studies, the New Zealand mud snail - Potamopyrgus antipodarum (Gray, 1853; Gastropoda, Tateidae) - was used as a barrier between the miracidia of Trichobilharzia regenti and the target snails Radix balthica. Since the presence of non-indigenous snails reduced the parasite prevalence under laboratory conditions, we posed three new research questions: (1) Do bird schistosomes show totally perfect efficacy for chemotactic swimming behavior? (2) Do the larvae respond to substances emitted by incompatible snail species? (3) Do the excretorysecretory products of incompatible snail species interfere with the search for a compatible snail host? The experiments were carried out in choice-chambers for the miracidia of $T$. regenti and $T$. szidati. The arms of the chambers, depending on the variant, were filled with water conditioned by $P$. antipodarum, water conditioned by lymnaeid hosts, and dechlorinated tap water. Miracidia of both bird schistosome species chose more frequently the water conditioned by snails - including the water conditioned by the incompatible lymnaeid host and the alien species, $P$. antipodarum. However, species-specific differences were noticed in the behavior of miracidia. $T$. regenti remained more often inside the base arm rather than in the arm filled with water conditioned by $P$. antipodarum or the control arm. T. szidati, however, usually left the base arm and moved to the arm filled with water conditioned by $P$. antipodarum. In conclusion, the non-host snail excretory-secretory products may interfere with the snail host-finding behavior of bird schistosome miracidia and therefore they may reduce the risk of swimmer's itch. 
1 The chemotactic swimming behavior of bird schistosome miracidia in the presence of compatible

2 and incompatible snail hosts

3 Anna Marszewska Corresp., 1 , Anna Cichy $^{1}$, Jana Bulantová ${ }^{2}$, Petr Horák ${ }^{2}$, Elżbieta Żbikowska ${ }^{1}$

$5{ }^{1}$ Department of Invertebrate Zoology and Parasitology, Faculty of Biological and Veterinary

6 Sciences, Nicolaus Copernicus University in Torun, Torun, Poland

7 2Department of Parasitology, Faculty of Science, Charles University, Prague, Czechia

9 Corresponding Author: Anna Marszewska

10 Email address: anna.marszewska@umk.pl

\section{Abstract}

14 No effective method has yet been developed to prevent the threat posed by the emerging disease 15 - cercarial dermatitis (swimmer's itch), caused by infective cercariae of bird schistosomes 16 (Digenea: Schistosomatidae). In our previous studies, the New Zealand mud snail - Potamopyrgus 17 antipodarum (Gray, 1853; Gastropoda, Tateidae) - was used as a barrier between the miracidia of 18 Trichobilharzia regenti and the target snails Radix balthica. Since the presence of non-indigenous snails reduced the parasite prevalence under laboratory conditions, we posed three new research questions: (1) Do bird schistosomes show totally perfect efficacy for chemotactic swimming

21 behavior? (2) Do the larvae respond to substances emitted by incompatible snail species? (3) Do

22 the excretory-secretory products of incompatible snail species interfere with the search for a 
23 compatible snail host? The experiments were carried out in choice-chambers for the miracidia of

$24 T$. regenti and $T$. szidati. The arms of the chambers, depending on the variant, were filled with

25 water conditioned by P. antipodarum, water conditioned by lymnaeid hosts, and dechlorinated tap

26 water. Miracidia of both bird schistosome species chose more frequently the water conditioned by

27 snails - including the water conditioned by the incompatible lymnaeid host and the alien species,

28 P. antipodarum. However, species-specific differences were noticed in the behavior of miracidia.

29 T. regenti remained more often inside the base arm rather than in the arm filled with water

30 conditioned by $P$. antipodarum or the control arm. T. szidati, however, usually left the base arm

31 and moved to the arm filled with water conditioned by $P$. antipodarum. In conclusion, the non-

32 host snail excretory-secretory products may interfere with the snail host-finding behavior of bird

33 schistosome miracidia and therefore they may reduce the risk of swimmer's itch.

\section{Keywords}

Trichobilharzia spp., Potamopyrgus antipodarum, lymnaeid hosts, miracidia, chemo-orientation

39 Corresponding Author:

40 Anna Marszewska ${ }^{1}$

41 Lwowska 1, Torun, 87-100, Poland

42 Email address: anna.marszewska@umk.pl 
46 Cercarial dermatitis (swimmer's itch) caused by bird schistosomes (Digenea: Schistosomatidae) is

47 considered an emerging disease in Europe (Horák et al., 2015; Tracz et al., 2019). These parasites

48 have a complex life cycle. The intermediate hosts are freshwater snails, whereas the final hosts are

49 predominantly waterfowl. Snails infected with bird schistosomes release huge numbers of

50 infective cercariae (Soldánová, Selbach \& Sures, 2016). Thus, even with a low prevalence of bird

51 schistosomes in intermediate host populations, there is a real threat for final hosts (Marszewska et

52 al., 2016). As a result of the similarity of some lipid components in the integument of humans and

53 birds, bird schistosome cercariae can accidentally penetrate the skin of people swimming or

54 wading in the water (Haas \& van de Roemer, 1998). An attack by many infective larvae may be

55 accompanied by some additional reactions, such as diarrhea, nausea, limb and lymph node

56 swelling, and/or fever (Horák et al., 2015). The removal of freshwater snails, the source of

57 infective cercariae, and waterfowl, the source of miracidia infective for the snails, from the

58 environment to reduce the risk of human swimmer's itch provides equivocal effects (Lévesque et

59 al., 2002; Jouet et al., 2008). Also, chemical methods such as the use of molluscicides may have

60 an adverse impact on local fauna (McCullough, 1992). An increasing number of cercarial

61 dermatitis outbreaks from year to year (Marszewska et al., 2016; Tracz et al., 2019), as well as

62 alarming data on bird schistosome migration inside the body of experimental mammals (Horák \&

63 Kolářová, 2001; Horák et al., 2008) stimulated our interest in the biological control that would be

64 applicable, especially in recreational water bodies.

65 Prevalence of digeneans in snails may be significantly reduced when a non-host snail species

66 occurs in sympatry with the target snails and miracidia - the first larval stages of the parasites

67 (Kalbe, Haberl \& Haas, 1997). In detail, snail-finding by miracidia is influenced by several

68 factors. The larvae react to, for example, the chemical cues secreted by snails (Hertel et al., 2006; 
Seppälä \& Leicht, 2015), and light stimuli (Gryseels et al., 2006) with changes in movement. The larvae have a limited lifespan (Anderson et al., 1982) and may exhaust their penetration enzymes and energy reserves during unsuccessful penetration attempts (Combes \& Moné, 1987), or they can penetrate into incompatible snails whose plasma kills the unspecific species of digenean trematodes (Sapp \& Loker, 2000).

Free-living larvae of parasites and their hosts live in the midst of a complex biocenosis; as a result, their transmission takes place within a diverse community of non-host organisms that can have a huge influence on the success or failure of parasite transmission (Hopper, Poulin \& Thieltges, 2008). The phenomenon of the reduction of disease risk as a result of the increased diversity of co-occurring non-host species is commonly known as the "dilution effect" (Keesing, Holt \& Ostfeld, 2006; Kopp \& Jokela, 2007; Johnson \& Thieltges, 2010; Cichy et al., 2016). Studies have shown several ways how these non-host organisms can disrupt parasite transmission, e.g., by acting as physical barriers (Christensen, 1979), predation, i.e., active feeding on larvae (Thieltges et al., 2008; Thieltges, Jensen \& Poulin, 2008; Vielma et al., 2019), non-host filter-feeders (Mouritsen \& Poulin, 2003; Hopper, Poulin \& Thieltges, 2008; Marszewska \& Cichy, 2015; Selbach, Rosenkranz \& Poulin, 2019) or decoys attracting the parasites (Thieltges, Jensen \& Poulin, 2008). However, not all non-host species are of equal importance as diluters (Hopper, Poulin \& Thieltges, 2008). For example, Hopper, Poulin \& Thieltges (2008) demonstrated that only selected filter-feeding species have a significant influence on the transmission of cercariae by feeding on these larvae, while other sympatric filter-feeders have no measurable effects on metacercariae formation in target second intermediate host. Kopp \& Jokela (2007) showed that particularly alien species can be involved in the "dilution effect", i.e., the snail species incompatible for an infectious agent can serve as a local protective shield for compatible hosts. 
92 For example, Lymnaea stagnalis (Linnaeus, 1758) (Gastropoda: Pulmonata), a species non-native

93 to New Zealand, serves as a defender of the native Potamopyrgus antipodarum (Gray, 1843)

94 (Gastropoda: Tateidae) against the trematode Microphallus sp. (Digenea: Microphallidae) (Kopp

$95 \&$ Jokela, 2007). In our previous study (Marszewska et al., 2018), we made a successful attempt

96 to experimentally use $P$. antipodarum, a snail species non-native to Europe, to interfere with the

97 finding of a compatible lymnaeid host by bird schistosome miracidia.

98 On the other hand, it should be emphasized that nonindigenous animal species may become 99 competent hosts for indigenous parasites (Kelly et al., 2009), or can be the source of pathogens 100 with a possible/unpredictable effect on domestic fauna. In the native range, $P$. antipodarum is 101 widely used by numerous digenean species, but there are no reports of bird schistosome infestation 102 (Hechinger, 2012; Selbach, Rosenkranz \& Poulin, 2019). However, P. antipodarum living in 103 European waters is extremely rarely infected with a pre-patent and/or a patent invasion of digenean 104 parasites (Gérard \& Le Lannic, 2003; Żbikowski \& Żbikowska, 2009; Gérard et al., 2017). In 105 addition, $P$. antipodarum infection by some bird schistosome species failed under experimental 106 conditions (Rind, 1989; Marszewska et al., 2018).

107 We hypothesize that any interference with snail host-finding by bird schistosome miracidia might 108 influence the risk of swimmer's itch. Thus, the aim of the present research was to examine (1) 109 whether the miracidia of bird schistosomes show totally perfect efficacy for chemotactic 110 swimming behavior, (2) whether the larvae respond to substances emitted by incompatible snail 111 species, (3) whether the excretory-secretory products of incompatible snail species disturb the 112 search for a compatible snail host. 
114 Materials and Methods

115

116 Obtaining miracidia

117 Two specimens of definitive hosts - Anas platyrhynchos f. dom. - were experimentally infected 118 by Trichobilharzia regenti (Digenea: Schistosomatidae), and two specimens of the same duck 119 species were experimentally infected by $T$. szidati (Digenea: Schistosomatidae) according to the 120 procedure described by Meuleman, Huyer \& Mooij 1983).

121 In order to obtain $T$. regenti eggs, the host nasal conchae were isolated during necropsy 20 days 122 post infection (dpi), while the bird droppings were collected 18 dpi to obtain T. szidati eggs.

123 Experimental duck hosts were euthanized by inhalation of isoflurane followed by decapitation.

124 The collected biological material with eggs was placed in dark long-necked flasks with 125 dechlorinated tap water at $20^{\circ} \mathrm{C}$. After a few minutes, having hatched the first larval stages 126 (miracidia) were clustered under the illuminated water surface. The miracidia were then 127 individually collected with a micropipette.

\section{Animal ethics statement}

130 Care and maintenance of experimental animals were carried out in accordance with European Directive 2010/63/EU and Czech law (246/1992 and 359/2012) for biomedical research involving animals. Experiments were performed with the legal consent of the Expert Committee of the

133 Section of Biology, Faculty of Science, Charles University, Prague, Czech Republic, and the 134 Ministry of Education, Youth and Sports of the Czechia under ref. no. MSMT-33740/2017-2 


\section{Water conditioning process}

137 As to the snail species, we prepared 3 types of conditioned water: (1) young individuals of Radix lagotis (Gastropoda: Pulmonata) (compatible host to T. regenti) - shell height of 6 (SE 0.1) mm; (2) young individuals of L. stagnalis (compatible host to T. szidati) - shell height of 9 (SE 0.3) mm; (3) adult parthenogenetic females of P. antipodarum - shell height of 3 (SE 0.2) mm. We used younger (smaller) lymnaeid snail individuals to increase the number of snails for water conditioning to reduce the impact of individual characteristics of particular specimens. Lymnaeid snails came from our laboratory breeding, whereas $P$. antipodarum came from the natural environment - Sosno Lake, Poland $\left(53^{\circ} 20^{\prime} 15^{\prime \prime} \mathrm{N}, 19^{\circ} 20^{\prime} 55^{\prime \prime} \mathrm{E}\right)$; before the experiments they were examined by non-invasive method for the presence of patent invasions (Żbikowska et al., 2006). So far, no pre-patent invasion of $P$. antipodarum has been reported in Sosno Lake (Cichy et al., 147 2017; Marszewska et al., 2018).

148 The water conditioning process was conducted in beakers at room temperature. Inside each beaker, $5 \mathrm{~g}$ of living snails (97 individuals of R. lagotis, 60 individuals of L. stagnalis or 116 individuals of $P$. antipodarum) in $100 \mathrm{ml}$ of dechlorinated water were kept for $2 \mathrm{~h}$. This concentration was used to assure enough quantity of an emitted substance in case it had a low effect. After the

152 incubation, the snail-conditioned water was filtered through filter paper. Only freshly prepared 153 substances no older than 24 hours were used in the experiment. 
156 The experiment was carried out in choice-chambers (Fig. 1) designed by Haberl et al. (1995). The

157 larvae were released from the base arm (Fig. 1) with $1 \mathrm{ml}$ of dechlorinated tap water to choose

158 between two side arms. Depending on the variant (Table 1), the side arms were filled with $1 \mathrm{ml}$ of

159 water conditioned by $P$. antipodarum, water conditioned by lymnaeid hosts and/or dechlorinated

160 tap water. Each variant of the experiment was performed in three series of 10 repetitions at $20^{\circ} \mathrm{C}$

161 under standardized artificial even lighting. These series were conducted within a few minutes

162 directly one after another.

163 In total, 30 replicates were performed for each parasite species per variant. One larva was placed 164 in the base arm of the choice-chamber (Fig. 1) for each repetition. A new larva was used for each

165 replicate. After 3 minutes, the junction between all the arms was closed and the location of the 166 larvae was checked under a stereoscopic microscope. The entire arm including part of the 167 migratory channel (Fig. 1) was considered the choice of the larva. The choice-chambers were 168 thoroughly washed and dried before each use.

\section{Statistical analysis}

171 We used a binomial test (Zar, 1984) to assess if the occupation of the side arms by larvae departed

172 from the random distribution (assuming 50\% probability of entering each arm) (Table 1). The tests

173 were performed separately for each variant and species of the parasite, taking only the larvae 174 present in the side arms (B1 and B2, Fig. 1) into account. Analyses were conducted in Microsoft 175 Excel (version 2013). 
179 In the control experiment (dechlorinated tap water versus dechlorinated tap water) the miracidia 180 of both bird schistosomes, T. regenti and T. szidati, occupied arms of the choice-chamber in similar 181 proportions (Table SM1, 2), and there were no significant statistical differences (a binomial test: $182 p=0.4, p=0.5$, respectively) (Fig. $2, \mathrm{I})$.

183 In the experiments with lymnaeid snail-conditioned water versus dechlorinated tap water (variants:

184 II, III (Table 1)) statistically significant differences were observed in the distribution of miracidia 185 (a binomial test: T. regenti - variant II: $p<0.001$, variant III: $p<0.01$; T. szidati - variant II: $p<$ 1860.001 , variant III: $p=0.001)$ (Fig. 2, II-III). In variant IV, a higher number of larvae moved to $P$. antipodarum-conditioned water than to dechlorinated tap water for both parasite species, but statistically significant differences were recorded only for T. szidati (a binomial test: $\mathrm{p}=0.001$ ) (T. regenti - a binomial test: $\mathrm{p}=0.2$ ). For the variant with $T$. regenti, only one-third of the larvae left the base arm. We were also able to observe statistically significant differences in variant $\mathrm{V}$ for T. szidati (a binomial test: $p=0.04$ ). There was no significant statistical difference in variant $\mathrm{V}$ for T. regenti (a binomial test: $p=0.08$ ). For both species of miracidia in variant $\mathrm{V}$, we observed a higher number of the larvae in the arms filled by compatible lymnaeid host-conditioned water than those filled by incompatible lymnaeid host-conditioned water (Fig. 2, V).

There were no statistically significant differences in the variants VI and VII (lymnaeid snailconditioned water versus $P$. antipodarum-conditioned water) (a binomial test: $T$. regenti - variant VI: $p=0.06$, variant VII: $p=0.06$; T. szidati - variant VI: $p=0.5$, variant VII: $p=0.3$ ). But, for miracidia of $T$. regenti, we observed a higher number of larvae in the arms filled by lymnaeid snailconditioned water (compatible and incompatible) than by P. antipodarum-conditioned water, 
200 whereas for miracidia of T. szidati, the distribution of larvae in the arms was similar (Fig. 2, VI201 VII).

202

\section{Discussion}

204

205

The majority of digenean species show a high specificity for their first intermediate hosts (Sapp \& Loker, 2000). The phenomenon is also observed for species belonging to the genus of

Trichobilharzia (Kock, 2001). It is also well known that many digeneans use chemo-orientation to find suitable hosts in the water column(Haas, 2003). Kalbe, Haberl \& Haas (1997) showed that the miracidia preferred water conditioned by their specific host snails compared to incompatible snail species, and did not respond to water conditioned by leeches, tadpoles, and fish. Our study supports these findings and shows that bird schistosome miracidia significantly more often choose water conditioned by host snails than unconditioned water (Fig. 2, II). However, our results indicate that bird schistosomes respond also to the excretory-secretory products of non-host snails

214 (Fig. 2, III), leading to the interference with miracidial chemo-orientation towards the host and non-host snail-conditioned water (T. regenti - Fig. 2, V, VI; T. szidati - Fig. VI). These 216 observations coincide with the results of many authors (Kalbe, Haberl \& Haas, 1996; Haberl et al., 2000; Kalbe, Haberl \& Haas, 2000; Haas, 2003; Hassan et al., 2003; Kalbe et al., 2004), who

218 showed some strains of Schistosoma mansoni could not distinguish between their specific and five incompatible host species. This behavior of miracidia indicates the adaptive plasticity of the 220 parasite or the similarity of individual components present in the range of snail-derived 221 stimulators. 
222 Generally, our results present differences in the accuracy of chemotactic swimming behavior of

223 the miracidia of bird schistosomes. The miracidia of $T$. regenti react to substrates from the host

224 snails and from the snails closely related to the suitable hosts to such an extent that it interferes

225 with finding the substrate from the target species. The larvae of $T$. szidati, despite reacting to non-

226 host lymnaeid snails, in the vast majority cope with finding a suitable substrate in the variant

227 consisting of non-host lymnaeid snail-conditioned water and host lymnaeid snail-conditioned

228 water. It is well known that the used bird schistosome species migrate through the body of the final

229 host in different ways, and also their eggs enter the external environment in other ways (Horák et

230 al., 2015). Perhaps these differences then have their reflection in the accuracy of the first larval

231 stages (hatched from the eggs) in search of a suitable host snail.

232 As to the species-specific reactions, $T$. szidati larvae more often choose water conditioned by $P$.

233 antipodarum than dechlorinated tap water, while $T$. regenti larvae more often remain in the base

234 arm (Fig. 2, IV). We know that the individual species of miracidia are adapted to the behavioral

235 patterns of compatible snail species (Behrens \& Nollen, 1992). Lymnaea stagnalis lives primarily

236 at the water surface on aquatic plants, while young individuals of Radix spp. often form high-

237 density populations covering the lake bottom in the shallow littoral zone, similar to P. antipodarum

238 (Piechocki \& Wawrzyniak-Wydrowska, 2016). We can only assume that the differences in the

239 response of bird schistosome larvae to the $P$. antipodarum-conditioned water may be related to the

240 above-mentioned difference between lymnaeid snail species.

241 Our observation is the first indication of these subtle differences in miracidial chemotactic

242 swimming behavior, and the phenomenon merits further research.

\section{Conclusions}


246 Based on our previous (Marszewska et al., 2018) and present results it seems that the increased

247 biodiversity of malacofauna may interfere with the life cycle of bird schistosomes (snail host-

248 finding and penetration) and thus, it can potentially reduce the risk of swimmer's itch. To prove

249 this possibility, we plan to test in the future not only the chemotactic behavior/chemical cues, but

250 also the ability of bird schistosome miracidia to penetrate the incompatible snail host $(P$.

251 antipodarum in our case). Moreover, currently conducted large-scale field research should answer

252 whether this non-native snail is occurring in lakes at sufficiently high densities to interfere with

253 the spread of swimmer's itch.

254

255 Acknowledgments

256

257 We would like to thank Mrs. Hazel Pearson - the native speaker of English - for proofreading of 258 an English version of the manuscript and Professor Jarosław Kobak (Nicolaus Copernicus 259 University in Torun) for help in conducting statistical analysis.

\section{References}

Anderson RM, Mercer JG, Wilson RA, Carter NP. 1982. Transmission of Schistosoma mansoni from man to snail: experimental studies of miracidial survival and infectivity in relation to larval age, water temperature, host size and host age. Parasitology 85 (2):339-360.

Behrens AC, Nollen PM. 1992. Responses of Echinostoma caproni miracidia to gravity, light, and chemicals. International Journal for Parasitology 22 (5):673-675. 
268 Christensen NO. 1979. Schistosoma mansoni: interference with cercarial host-finding by various

269 aquatic organisms. Journal of Helminthology 53 (1):7-14.

270 Cichy A, Marszewska A, Parzonko J, Żbikowski J, Żbikowski E. 2017. Infection of 271 Potamopyrgus antipodarum (Gray, 1843) (Gastropoda: Tateidae) by trematodes in Poland, 272 including the first record of aspidogastrid acquisition. Journal of Invertebrate Pathology $273 \quad 150: 32-34$.

274 Cichy A, Urbańska M, Marszewska A, Andrzejewski W, Żbikowska E. 2016. The invasive 275 Chinese pond mussel Sinanodonta woodiana (Lea, 1834) as a host for native symbionts in 276 European waters. Journal of Limnology 75 (2):288-296.

277 Combes C, Moné H. 1987. Possible mechanisms of the decoy effect in Schistosoma mansoni 278 transmission. International Journal for Parasitology 17 (4).

279 Gérard C, Le Lannic J. 2003. Establishment of a new host-parasite association between the 280 introduced invasive species Potamopyrgus antipodarum (Smith) (Gastropoda) and 281 Sanguinicola sp. Plehn (Trematoda) in Europe. Journal of Zoology 261 (2):213-216.

282
Gérard C, Miura O, Lorda J, Cribb TH, Nolan MJ, Hechinger RF. 2017. A native-range source for a persistent trematode parasite of the exotic New Zealand mudsnail (Potamopyrgus antipodarum) in France. Hydrobiologia 785 (1):115-126.

Gryseels B, Polman K, Clerinx J, Kestens L. 2006. Human schistosomiasis. The Lancet 368 (9541):1106-1118.

Haas W. 2003. Parasitic worms: strategies of host finding, recognition and invasion. Zoology 106 (4):349-364. 
289 Haas W, van de Roemer A. 1998. Invasion of the vertebrate skin by cercariae of Trichobilharzia 290 ocellata: penetration processes and stimulating host signals. Parasitology Research 84

291

292

293

294

295

296

297

298

299

300

301

302

303

304

305

306

307

308

309

310

311 (10):787-795.

Haberl B, Kalbe M, Fuchs H, Ströbel M, Schmalfuss G, Haas W. 1995. Schistosoma mansoni and S. haematobium: Miracidial host-finding behaviour is stimulated by macromolecules. International Journal for Parasitology 25 (5):551-560.

Haberl B, Körner M, Spengler Y, Hertel J, Kalbe M, Haas W. 2000. Host-finding in Echinostoma caproni: miracidia and cercariae use different signals to identify the same snail species. Parasitology 120 (Pt 5):479-486.

Hassan AHM, Haberl B, Hertel J, Haas W. 2003. Miracidia of an Egyptian strain of Schistosoma mansoni differentiate between sympatric snail species. The Journal of parasitology 89 (6):1248-1250.

Hechinger RF. 2012. Faunal Survey And Identification Key For The Trematodes (Platyhelminthes: Digenea) Infecting Potamopyrgus Antipodarum (Gastropoda: Hydrobiidae) As First Intermediate Host. Zootaxa 3418:1-27.

Hertel J, Holweg A, Haberl B, Kalbe M, Haas W. 2006. Snail odour-clouds: spreading and contribution to the transmission success of Trichobilharzia ocellata (Trematoda, Digenea) miracidia. Oecologia 147 (1):173-180.

Hopper JV, Poulin R, Thieltges DW. 2008. Buffering role of the intertidal anemone Anthopleura aureoradiata in cercarial transmission from snails to crabs. Journal of Experimental Marine Biology and Ecology 367 (2):153-156.

Horák P, Kolářová L. 2001. Bird schistosomes: do they die in mammalian skin? Trends in Parasitology 17 (2):66-69. 
312 Horák P, Mikeš L, Lichtenbergová L, Skála V, Soldánová M, Brant SV. 2015. Avian 313 schistosomes and outbreaks of cercarial dermatitis. Clinical Microbiology Reviews 28 (1):165$314 \quad 190$.

315 Horák P, Mikeš L, Rudolfová J, Kolářová L. 2008. Penetration of Trichobilharzia cercariae into 316 mammals: dangerous or negligible event? Parasite 15:299-303.

317 Johnson PTJ, Thieltges DW. 2010. Diversity, decoys and the dilution effect: how ecological 318 communities affect disease risk. The Journal of Experimental Biology 213 (6):961-970.

Jouet D, Ferté H, Depaquit J, Rudolfová J, Latour P, Zanella D, Kaltenbach ML, Léger N. 2008. Trichobilharzia spp. in natural conditions in Annecy Lake, France. Parasitology Research 103 (1):51-58.

Kalbe M, Haberl B, Haas W. 1996. Schistosoma mansoni miracidial host-finding: species specificity of an Egyptian strain. Parasitology Research 82 (1):8-13.

Kalbe M, Haberl B, Haas W. 1997. Miracidial host-finding in Fasciola hepatica and Trichobilharzia ocellata is stimulated by species-specific glycoconjugates released from the host snails. Parasitology Research 83 (8):806-812.

Kalbe M, Haberl B, Haas W. 2000. Snail host finding by Fasciola hepatica and Trichobilharzia ocellata: compound analysis of "miracidia-attracting glycoproteins". Experimental Parasitology 96 (4):231-242.

Kalbe M, Haberl B, Hertel J, Haas W. 2004. Heredity of specific host-finding behaviour in Schistosoma mansoni miracidia. Parasitology 128 (Pt 6):635-643.

Keesing F, Holt RD, Ostfeld RS. 2006. Effects of species diversity on disease risk. Ecology Letters 9 (4):485-498. 
334 Kelly DW, Paterson RA, Townsend CR, Poulin R, Tompkins DM. 2009. Parasite spillback: a

335 neglected concept in invasion ecology? Ecology 90 (8):2047-2056.

336 Kock S. 2001. Investigations of intermediate host specificity help to elucidate the taxonomic status

337 of Trichobilharzia ocellata (Digenea: Schistosomatidae). Parasitology 123 (1):67-70.

338 Kopp K, Jokela J. 2007. Resistant invaders can convey benefits to native species. Okois 116:295$339 \quad 301$.

Lévesque B, Giovenazzo P, Guerrier P, Laverdière D, Prud'Homme H. 2002. Investigation of an outbreak of cercarial dermatitis. Epidemiology and Infection 129 (2):379-386.

Marszewska A, Cichy A. 2015. Unionid clams and the zebra mussels on their shells (Bivalvia: 
356 Mouritsen KN, Poulin R. 2003. The mud flat anemone-cockle association: mutualism in the

357 intertidal zone? Oecologia 135 (1):131-137.

358 Piechocki A, Wawrzyniak-Wydrowska B. 2016. Guide to freshwater and marine mollusca of

359 Poland. Poznań: Bogucki Wydawnictwo Naukowe.

360 Rind S. 1989. Dendritobilharzia pulverulenta (Trematoda: Schistosomatidae) in New Zealand.

$361 \quad$ New Zealand Journal of Zoology 16 (2):215-220.

362 Sapp KK, Loker ES. 2000. Mechanisms underlying digenean-snail specificity: role of miracidial

363 attachment and host plasma factors. Journal of Parasitology 86 (5): 1012-1020.

364 Selbach C, Rosenkranz M, Poulin R. 2019. Cercarial behavior determines risk of predation. The Journal of Parasitology 105 (2):330-333.

Seppälä O, Leicht K. 2015. Quality attracts parasites: host condition-dependent chemo-orientation of trematode larvae. Functional Ecology 29 (6):791-795.

368

369

370

371

372

373

374

375

376

377

378

Soldánová M, Selbach C, Sures B. 2016. The early worm catches the bird? Productivity and patterns of Trichobilharzia szidati eercarial emission from Lymnaea stagnalis. PLOS One 11 (2):e0149678.

Thieltges DW, Bordalo MD, Hernández AC, Prinz K, Jensen KT. 2008. Ambient fauna impairs parasite transmission in a marine parasite-host system. Parasitology 135 (9):1111-1116.

Thieltges DW, Jensen KT, Poulin R. 2008. The role of biotic factors in the transmission of freeliving endohelminth stages. Parasitology 135 (4):407-426.

Tracz ES, Al-Jubury A, Buchmann K, Bygum A. 2019. Outbreak of swimmer's itch in Denmark. Acta Dermato-Venereologica 99 (12):1116-1120.

Vielma S, Lagrue C, Poulin R, Selbach C. 2019. Non-host organisms impact transmission at two different life stages in a marine parasite. Parasitology Research 118 (1):111-117. 
379 Zar JH. 1984. Biostatistical Analysis. Englewood Cliffs: Prentice Hall.

380 Żbikowska E, Kobak J, Żbikowski J, Kaklewski J. 2006. Infestation of Lymnaea stagnalis by

381 digenean flukes in the Jeziorak Lake. Parasitology Research 99 (4):434-439.

382 Żbikowski J, Żbikowska E. 2009. Invaders of an invader-trematodes in Potamopyrgus

383 antipodarum in Poland. Journal of Invertebrate Pathology 101 (1):67-70.

384

385

386

387

388

389

390

391

392

393

394

395

396

397

398

Peer] reviewing PDF | (2020:02:46196:3:0:NEW 8 Jun 2020) 


\section{Figure captions}

Figure 1. The choice-chamber for evaluation of bird schistosome miracidial chemotactic swimming behavior (channel depth: $3 \mathrm{~mm}$ ): A - base arm, B1 and B2 - side arms, C - closure

Figure 2. The number of miracidia in the side arms per series (A-G - variants numbers from I to VII, respectively, for T. regenti; H-N - variants numbers from I to VII, respectively, for T. szidati; Water - dechlorinated tap water; CLH - compatible lymnaeid host-conditioned water: R. lagotis for $T$. regenti and L. stagnalis for $T$. szidati; InCLH - incompatible lymnaeid host-conditioned water: L. stagnalis for T. regenti and R. lagotis for T. szidati; $\mathrm{Pa}-P$. antipodarum; * - statistically significant a binomial test $(p<0.05))$ 
Figure 1

The choice-chamber for evaluation of bird schistosome miracidial chemotactic swimming behavior (channel depth: $3 \mathrm{~mm}$ )

A - base arm, B1 and B2 - side arms, C - closur

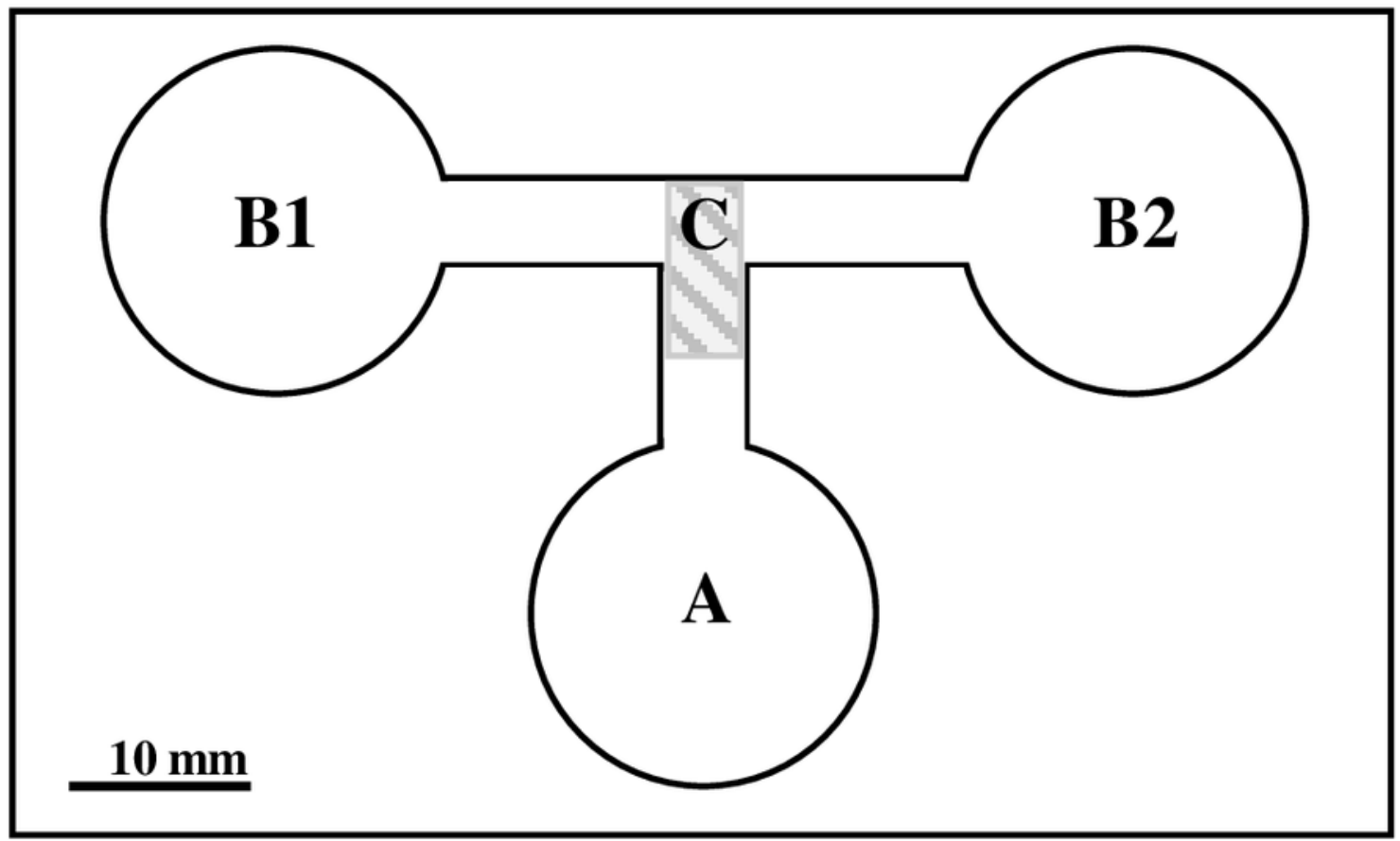




\section{Figure 2}

The number of miracidia in the side arms per serie

A-G - variants numbers from I to VII, respectively, for $T$. regenti; $\mathrm{H}-\mathrm{N}$ - variants numbers from I to VII, respectively, for T. szidati; Water - dechlorinated tap water; CLH - compatible lymnaeid host -conditioned water: $R$. lagotis for $T$. regenti and $L$. stagnalis for $T$. szidati; InCLH - incompatible lymnaeid host-conditioned water: L. stagnalis for $T$. regenti and $R$. lagotis for T. szidati; Pa - P. antipodarum; * - statistically significant a binomial test $(p<0.05)$ 

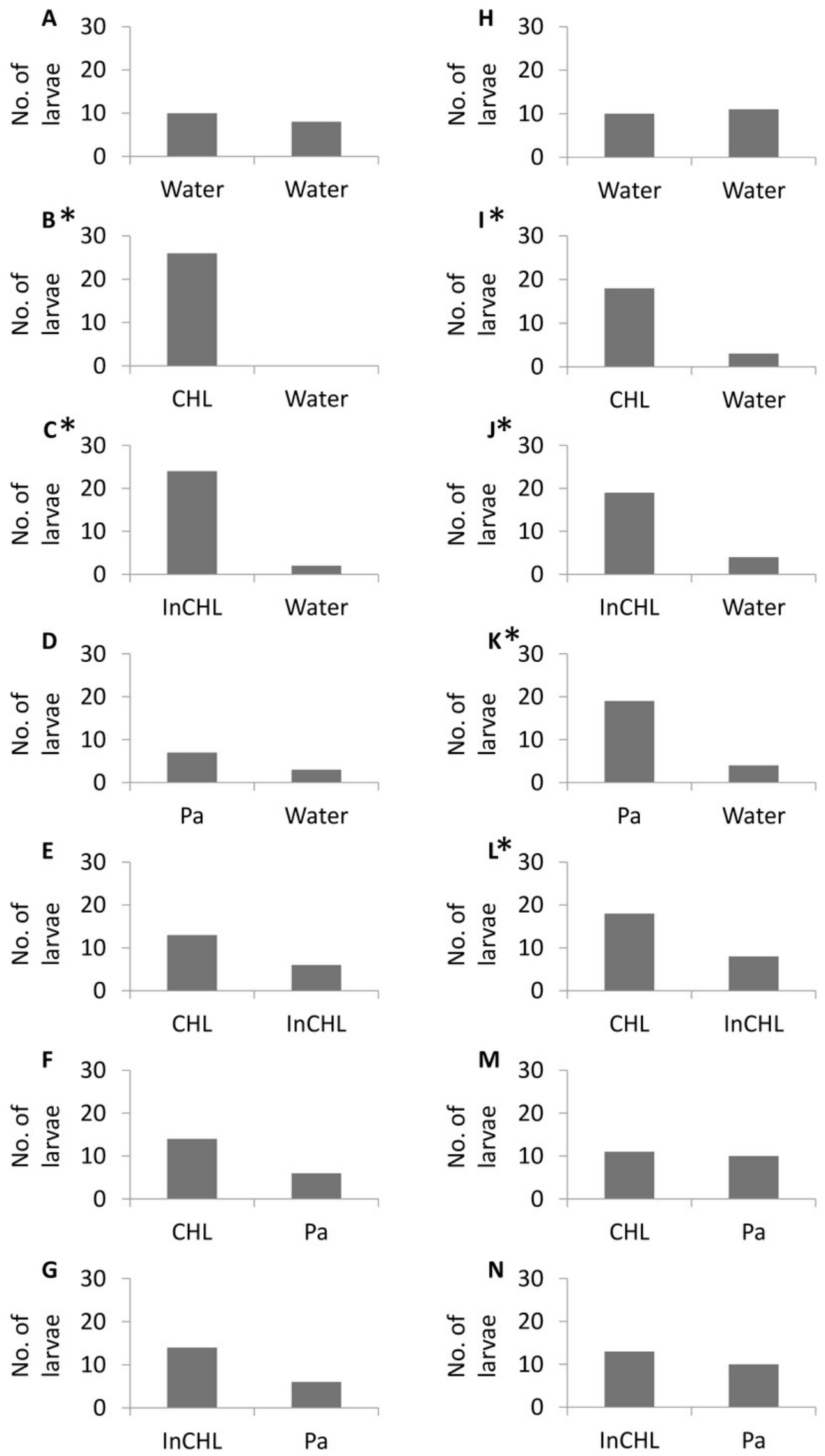


\section{Table $\mathbf{1}$ (on next page)}

The used experimentally variants

${ }^{*}$ - Control experiment; ${ }^{* *}-$ R. lagotis for T. regenti and L. stagnalis for T. szidati ; ${ }^{* * *}-$ L. stagnalis for $T$. regenti and $R$. lagotis for $T$. szidati 
1 Table 1. The used experimentally variants

\begin{tabular}{lll}
\hline No & First arm & Second arm \\
\hline I* $^{*}$ & Dechlorinated tap water & Dechlorinated tap water \\
II & Compatible lymnaeid host ${ }^{* *}$ & Dechlorinated tap water \\
III & Incompatible lymnaeid host & Dechlorinated tap water \\
IV & Potamopyrgus antipodarum & Dechlorinated tap water \\
V & Compatible lymnaeid host & Incompatible lymnaeid host \\
VI & Compatible lymnaeid host & Potamopyrgus antipodarum \\
VII & Incompatible lymnaeid host & Potamopyrgus antipodarum \\
\hline
\end{tabular}

2 *- Control experiment; ${ }^{* *}-$ R. lagotis for T. regenti and L. stagnalis for T. szidati; ${ }^{* * *}-$ L. stagnalis

3 for T. regenti and R. lagotis for T. szidati 